\title{
MENINGKATKAN KEMAMPUAN BERHITUNG PADA ANAK USIA DINI DENGAN MENGGUNAKAN METODE JARIMATIKA
}

\author{
Lisa Agave Aritonang ${ }^{1}$, Dewi Safitri Elshap ${ }^{2}$ \\ ${ }^{1}$ IKIP Siliwangi, Cimahi \\ ${ }^{2}$ IKIP Siliwangi, Cimahi \\ ${ }^{1}$ lisaagave@gmail.com, ${ }^{2}$ nauradewi14@yahoo.com
}

\begin{abstract}
This research is motivated by the problem of the ability of early childhood to begin with low initial arithmetic and the lack of interest of children in learning to count. So that researchers want to know and examine the ability to count children by using a new method that uses the Jarimatic method. The method used is a quasi-experimental method by class random sampling. The subjects in this study were students from one of the kindergartens in the Taman Kopo area of Bandung consisting of 17 students from each class, namely the experimental class and the control class. The data analysis technique was performed using SPSS 17.0 software with the statistical tests of normality, homogeneity and difference test of the two average pretest data and N-gain numeracy abilities of children. The results of the data show that the ability to count has increased after using the Jarimatic method, this is evident from the average results of the $\mathrm{N}$-gain experimental class that is in the medium category. So that the ability to count early children whose learning uses the Jarimatic method is better than children who learn using the ordinary method, so it can be concluded that the Jarimatic method can create a more enjoyable learning process and increase children's interest in learning to count.
\end{abstract}

Keywords: Ability to Count, Jarimatika, Early Childhood

\begin{abstract}
ABSTRAK
Penelitian ini dilatar belakangi oleh masalah kemampuan anak usia dini dalam behitung permulaan yang masih rendah dan kurangnya minat anak dalam pembelajaran berhitung. Sehingga peneliti ingin mengetahui dan menelaah tentang kemampuan berhitung anak dengan menggunakan metode baru yaitu menggunakan metode jarimatika. Metode yang digunakan adalah metode kuasi eksperimen dengan pengambilan sampel secara acak kelas. Subjek dalam penelitian ini adalah siswa dati salah satu Taman Kanak-kanak di daerah Taman Kopo Bandung yang terdiri dari 17 orang siswa dari masing-masing kelas yaitu kelas eksperimen dan kelas kontrol. Teknik analisis data dilakukan dengan menggunakan bantuan software SPSS 17.0 dengan uji statistik uji normalitas, homogenitas dan uji perbedaan dua rata-rata data pretest dan N-gain kemampuan berhitung anak. Hasil data menunjukkan bahwa kemampuan berhitung mengalami peningkatan setelah menggunakan metode jarimatika, hal ini terlihat dari hasil rata-rata N-gain kelas eksperimen yang berada pada kategori sedang. Sehingga kemampuan berhitung anak usia dini yang pembelajarannya menggunakan metode jarimatika lebih baik daripada anak yang pembelajarannya dengan menggunakan metode biasa, sehingga dapat disimpulkan bahwa metode jarimatika dapat menciptakan proses pembelajaran yang lebih menyenangkan dan meningkatkan minat anak terhadap pembelajaran berhitung.
\end{abstract}

Kata Kunci: Kemampuan berhitung, Jarimatika, Anak Usia Dini 


\section{JURNAL GERIA}

ISSN : 2614-6347(Print) 2714-4107 (Online)

Vol.2 | No.6 | November 2019

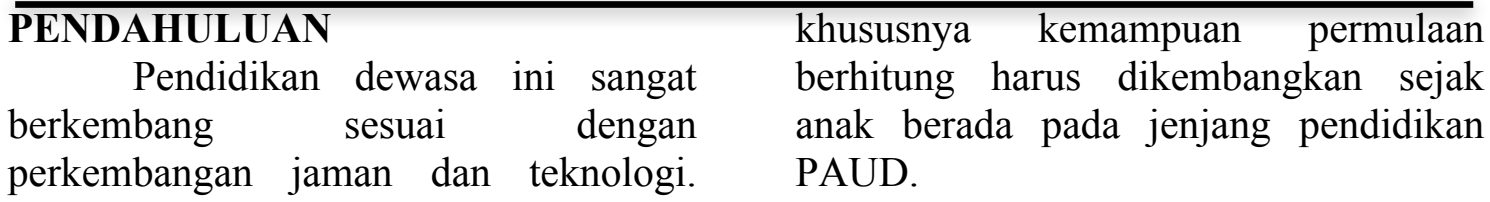

Pendidikan merupakan suatu hal yang penting diberikan pada anak-anak khususnya anak PAUD dan siswa taman kanak-kanak karena anak usia mereka masih dalam tahap perkembangan fisik dan psikomotrik yang dapat membentuk anak menjadi pribadi cerdas dan memiliki prilaku yang baik pada saat memasuki jenjang pendidikan yang lebih tinggi. Hal ini sejalan dengan (Elsap, 2018) yang menyatakan bahwa tujuan umum pendidikan nasional yaitu mencerdaskan kehidupan bangsa dan mengembangkan manusia Indonesia seutuhnya. Melalui pendidikan maka akan menambah wawasan bagi anak terutama pada anak PAUD dan TK.

Anak usia dini adalah individu yang sedang mengalami pertumbuhan dan pengembangan yang sangat pesat dan fundamental bagi kehidupan selanjutnya. Karena usia mereka merupakan usia emas untuk mendapatkan pendidikan khususnya dalam mengasah kemampuannya dalam berhitung. Menurut Lila (Purwaningsih, Reswita, \& Putri, 2018), usia dini merupakan periode emas (golden age) bagi tumbuh kembang anak untuk memperoleh pendidikan. Pendidikan tersebut meliputi aspek nilai agama, moral, kognitif, fsikomotorik, sosial dan budaya.

Salah satu bidang perkembangan yang dilakukan pada anak usia dini adalah aspek pengembangan kognitif. Perkembangan kognitif menurut Depdiknas (Musi, 2016) bertujuan agar anak mudah memahami pembelajaran yang disampaikan oleh guru, dapat memecahkan masalah dengan berbagai macam alternatif penyelesaian masalah, dapat mengembangkan kemampuan matematika dan dapat berpikir secara logis. Sehingga kemampuan kognitif

Kemampuan berhitung sangat penting diberikan pada anak usia dini karena kemampuan ini sangat erat kaitannya dengan kehidupan sosial dan bermanfaat dalam kehidupan sehari-hari. Hal ini sejalan dengan pendapat Depdiknas (Musi, 2016) yang menyatakan bahwa berhitung sangat berguna bagi kehidupan sehari-hari, terutama pada konsep bilangan yang merupakan dasar bagi pengembangan kemampuan matematis. Konsep berhitung pada pendidikan anak usia dini diperlukan untuk menumbuhkan pengetahuan dasar matematik yang akan berguna pada pendidikan yang akan ditempuh anak selanjutnya. Sehingga pada saat anak memasuki pendidikan yang lebih tinggi maka anak akan siap dengan pembelajaran berhitung dengan level yang lebih tinggi.

Sedangkan menurut (Oktariyani, 2017) menyatakan bahwa berhitung merupakan dasar dari beberapa ilmu yang dipakai dalam setiap kehidupan manusia yang kegiatannya tidak terlepas dari peran matematika didalamya, mulai dari penambahan, pengurangan, perkalian dan pembagian yang tidak pernah terlepas dari kehidupan manusia dan sangat berguna dalam kegiatan sehari-hari. Dengan menerapkan konsep berhitung pada anak sejak dini maka diharapkan anak akan mampu memahami konsep berhitung permulaan dengan baik.

Akan tetapi, kenyataan di lapangan beberapa anak pada usia dini masih mengalami kesulitan dalam memahami konsep tentang perhitungan karena terbatas pada metode pembelajaran yang masih menggunakan metode ceramah dan permainan tentang perhitungan yang kurang variatif . Sehingga sebagian anak terlihat bosan 


\section{JURNAL GERIA}

ISSN : 2614-6347(Print) 2714-4107 (Online)

Vol.2 | No.6 | November 2019

dan tidak berminat pada pembelajaran berhitung. Hal ini sejalan dengan hasil observasi yang dilakukan oleh (Patintingan, 2015) yang menyatakan bahwa beberapa anak masih mengalami kesulitan dalam memahami konsep benda yang jumlahnya lebih banyak atau lebih sedikit, sulit memahami makna angka 1 sampai 10 secara berurutan maju atau mundur, belum mampu membedakan simbol dan bilangannya sehingga berdampak pada rendahnya kemampuan anak dalam memahami konsep behitung dasar.

Untuk meningkatkan kemampuan konsep berhitung pada anak diperlukan suatu strategi pembelajaran yang inovatif dan kreatif yang direncanakan guru dalam proses pembelajaran agar proses pembelajaran tidak monoton dan siswa lebih aktif dalam mengikuti pembelajaran di kelas. Dengan adanya strategi tersebut maka tujuan pembelajaran dapat tercapai sesuai dengan yang dinginkan dan proses pembelajaran dapat lebih menyenangkan dan kondusif. Salah satu metode pembelajaran berhitung yang sering digunakan pada pembelajaran di TK adalah dengan menggunakan metode jarimatika. Metode jarimatika merupakan metode yang menggunakan jari dan dibuat menjadi lebih menyenangkan untuk anak-anak karena dapat memberikan visualisasi operasi hitung pada anak.

Menurut

Wulandari

(Purwaningsih et al., 2018), metode jarimatika adalah salah satu metode berhitung yang sering digunakan pada pembelajaran di TK yang sedang belajar pembagian, penjumlahan, perkalian dan pengurangan. Jarimatika adalah suatu cara menghitung matematika dengan menggunakan alat bantu jari. Sedangkan menurut Hardiyanti (Hardiyanti, Maulana, \& Julia, 2017), metode jarimatika adalah sebuah metode atau suatu cara belajar yang mudah serta menyenangkan bagi anak usia dini karena menggunakan media jari tangan dalam pembelajarannya yang dapat menarik minat anak dan menggunakan jari tangannya dalam belajar berhitung sehingga anak bisa menguasai konsep permulaan berhitung dengan baik.

Berdasarakan beberapa definisi di atas, dapat disimpulkan bahwa jarimatika merupakan salah satu metode yang dapat menarik minat anak dalam meningkatkan konsep berhitung karena pada proses pembelajarannya yang menarik dan menyenangkan sehingga dapat mengasah fsikomotorik anak dengan menggunakan jari-jari tangan dalam belajar berhitung. Oleh karena itu, peneliti ingin mengetahui dan menelaah peningkatan kemampuan berhitung anak usia dini di TKK Happy Holly Kids Taman Kopo Indah dengan menggunakan metode jarimatika

\section{METODOLOGI}

Metode yang digunakan dalam penelitian ini yaitu metode kuasi eksperimen. Pada kuasi eksperimen sampel tidak diacak secara acak subjek tetapi sampel diambil secara acak kelas dengan subjek seadanya. Desain penelitiannya yaitu menurut (Ruseffendi, 2010) sebagai berikut:

$\mathrm{A}=\mathrm{O} \quad \mathrm{X} \quad \mathrm{O}$

$\mathrm{A}=\mathrm{O} \quad \mathrm{O}$

Keterangan:

$\mathrm{X}$ : Perlakuan pembelajaran dengan menggunakan metode jarimatika

$\mathrm{O}$ : Pemberian pretes dan postes

A : Pengambilan sampel secara acak kelas

Penelitian ini dilaksanakan disalah satu sekolah Taman KanakKanak di kota Bandung. Populasi dari penelitian ini adalah TKK Happy Holy Kids di Taman Kopo Indah Blok C 1, sedangkan sampelnya diambil dari dua kelas secara acak dimana TK A 1 Happy 


\section{JURNAL GERIA}

ISSN : 2614-6347(Print) 2714-4107 (Online)

Vol.2 | No.6 | November 2019

Holy Kids untuk kelas eksperimen dan TK A 2 Happy Holy Kids untuk kelas kontrol. Subjek dari kedua kelas tersebut masing-masing terdiri dari 17 orang siswa.

Intrumen yang digunakan dalam penelitian ini adalah adalah seperangkat soal tes yang berbentuk uraian gambar dan soal yang terdiri dari 5 butir soal. Instrumen tersebut dikembangkan sendiri oleh peneliti dan telah diukur validitas, reabilitas, indeks kesukaran dan daya pembedanya.Kemudian hasil penelitian ini dianalisis dan diolah dengan menggunakan bantuan software SPSS 17.0 dengan uji statistik uji normalitas, homogenitas varians dan uji t serta uji ngain untuk mengetahui peningkatan dan pencapaian kemampuan berhitung anak dengan menggunakan metode jarimatika.

\section{HASIL DAN PEMBAHASAN}

Hasil

Penelitian ini bertujuan untuk meningkatkan kemampuan berhitung pada anak usia dini dengan menggunakan metode jarimatika. Analisis data yang dilakukan yaitu dengan menganalisis data hasil pretes yang bertujuan untuk menelaah kemampuan berhitung anak usia dini sebelum pemberian perlakuan dengan menggunakan metode jarimatika dan analisis data hasil postes untuk menelaah kemampuan berhitung anak usia dini setelelah diberikan pembelajaran dengan metode jarimatika. Kemudian, data N-gain untuk mengetahui peningkatan dan pencapaian kemampuan berhitung anak usia dini setelah diberi perlakuan.

Pengolahan data tes kemampuan berhitung ini berdasarkan hasil pretes dan data N-gain. Berdasarkan hasil penelitian mengenai kemampuan berhitung anak usia dini, maka didapatkan hasil yang dideskripsikan pada Tabel 1 berikut:
Tabel 1

Deskriptif Kemampuan Berhitung

\begin{tabular}{ccc}
\hline PAM & Experiments & Control \\
\hline $\begin{array}{c}\text { Nilai } \\
\text { Min }\end{array}$ & 10 & 8 \\
Nilai & 18 & 16 \\
Max & & \\
Rata-rata & 14,06 & 11,65
\end{tabular}

Skor Maksimal Ideal (SMI) $=20$

Untuk mengetahui peningkatan kemampuan berhitung pada anak dengan menggunakan metode jarimatika, maka dilakukan uji statistik pada data pretes dan N-gain dengan uji normalitas, homogenitas dan uji dua rata-rata.

Tabel 2

Hasil Uji Normalitas Data Pretes Kemampuan Berhitung

\begin{tabular}{|c|c|c|c|}
\hline & \multicolumn{3}{|c|}{ Shapiro Wilk } \\
\hline & Statistik & Df & Sig. \\
\hline Pretes & .858 & 17 & .014 \\
\hline Pretes & .916 & 17 & .125 \\
\hline
\end{tabular}

Berdasarkan Tabel 2 didapatkan nilai sig. sebesar 0,14 dan 0,125 pada skor pretes kelas eksperimen dan kelas kontrol. Karena nilai sig. $<0,05$ untuk kelas eksperimen, maka dapat disimpulkan bahwa data tersebut tidak berdistribusi normal. Karena data tidak berdistribusi normal, maka dilanjutkan dengan uji non-parametrik uji MannWhitney.

Tabel 3

Hasil Uji Mann-Whitney Data Pretes Kemampuan Berhitung

\begin{tabular}{|c|c|}
\hline & $\begin{array}{c}\text { Pretes } \\
\text { Kemampuan } \\
\text { Berhitung }\end{array}$ \\
\hline Mann Whitney & 135.500 \\
\hline Wilcoxon W & 288.500 \\
\hline Z & -.327 \\
\hline Asymp. sig. (2-tailed) & .744 \\
\hline
\end{tabular}




\section{JURNAL GERIA}

ISSN : 2614-6347(Print) 2714-4107 (Online)

Vol.2 | No.6 | November 2019

Berdasarkan Tabel 3 didapatkan nilai sig. $>0,05$ yaitu sebesar 0,744 , maka dapat disimpulkan bahwa kedua kelas tersebut memiliki kemampuan awal yang sama. Untuk mengetahui peningkatan kemampuan berhitung anak usia dini, maka dilakukan analasis data $\mathrm{N}$-gain dengan langkah-langkah yang dilakukan sama dengan langkah-langkah di atas

\section{Tabel 4}

Data Hasil Uji Normalitas Data N-gain Kemampuan Berhitung

\begin{tabular}{|c|c|c|c|}
\hline \multirow{2}{*}{} & \multicolumn{3}{|c|}{ Shapiro Wilk } \\
\cline { 2 - 4 } & Statistik & Df & Sig. \\
\hline N-gain & .832 & 17 & .006 \\
\hline N-gain & .953 & 17 & .503 \\
\hline
\end{tabular}

Berdasarkan Tabel 4 diperoleh nilai sig. sebesar 0,006 dan 0,503 untuk kelas eksperimen dan kelas kontrol. Karena nilai sig. salah satu kelas tersebut $<0,05$ maka dapat disimpulkan bahwa data tersebut tidak berdistribusi normal sehingga dilanjutkan dengan uji nonparametrik uji Mann Whitney.

Tabel 5

Hasil Uji Mann Whitney Data N-Gain Kemampuan Berhitung

\begin{tabular}{|c|c|}
\hline & $\begin{array}{c}\text { N- } \\
\text { gain_Kemampuan } \\
\text { Berhitung }\end{array}$ \\
\hline Mann Whitney & 89.500 \\
\hline Wilcoxon W & 242.500 \\
\hline Z & -1.899 \\
\hline $\begin{array}{c}\text { Asymp. sig. } \\
\text { (2-tailed) }\end{array}$ & .058 \\
\hline
\end{tabular}

Berdasarkan data di atas pada Tabel 5 diperoleh nilai sig. 0,058. Karena analisis data menggunakan SPSS, maka nilai sig./2 menurut Uyanto (Minarti \& Nurfauziah, 2016), sehingga $0,058 / 2=$ 0,029 , artinya nilai sig. $<0,05$ dapat diartikan bahwa peningkatan kemampuan berhitung pada anak usia dini yang pembelajarannya menggunakan metode jarimatika lebih baik daripada yang pembelajarannya dengan metode biasa.

\section{Pembahasan}

Untuk mengetahui kemampuan awal berhitung anak dilakukan pretes (tes awal) kemampuan berhitung dengan memberikan soal berupa soal uraian dan gambar yang terdiri dari 5 soal. Berdasarkan hasil analisis data pretes, tidak terdapat perbedaan kemampuan berhitung anak usia dini pada kelas eksperimen dan kelas kontrol. Artinya kemampuan awal berhitung kelas kontrol dan kelas ekseprimen memiliki kemampuan yang sama. Setelah dilakukan tes awal (pretes), peneliti memberikan pembelajaran yang berbeda, dimana pada kelas eksperimen menggunakan pembelajaran dengan menggunakan metode jarimatika dan kelas kontrol menggunakan pembelajaran dengan cara biasa. Hal ini mengakibatkan kemampuan berhitung pada anak TKK Hapy Holy Kids yang merupakan kelas eksperimen mengalami perubahan atau meningkat. Sehingga kemampuan berhitung anak yang pembelajarannya menggunakan metode jarimatika lebih baik daripada yang menggunakan pembelajaran biasa.

Peningkatan tersebut terlihat dari hasil rata-rata nilai $\mathrm{N}$-gain kelas eksperimen yang berada pada kategori sedang. Pada kelas eksperimen, siswa diberikan pembelajaran dengan menggunakan metode jarimatika sedangkan pada kelas kontrol siswa diberikan dengan pembelajaran biasa. Pada pembelajaran dengan menggunakan metode jarimatika ini melibatkan kegiatan yang menarik perhatian dan minat anak dalam berhitung karena pembelajarannya lebih bervariatif dan anak menjadi lebih aktif dalam proses pembelajaran. Kegiatan tersebut diantaranya yaitu kegiatan membilang 110 dan menjumlahkan serta mengurangi 


\section{JURNAL GERIA}

ISSN : 2614-6347(Print) 2714-4107 (Online)

Vol.2 | No.6 | November 2019

1-10 dengan menggunakan permainan dan jari-jari tangan. Kegiatan tersebut memungkinkan untuk melatih otak dan fsikomtorik anak sehingga anak menjadi lebih aktif, cerdas serta dapat meningkatkan kemampuan berhitung permulaan pada anak. Kemampuan berhitung permulaan pada anak usia dini bertujuan untuk memperkenalkan anak pada bilangan dan menggunakan hitungan yang berguna untuk kehidupannya sehari-hari.

Sedangkan pada kelas kontrol, siswa diberikan dengan pembelajaran biasa dengan menggunakan metode ceramah. Pada metode ceramah ini, pembelajaran terfokus pada guru sehingga siswa merasa bosan, kondisi kelas yang kurang kondusif dan kurangnya minat anak pada pembelajarannya berhitung sehingga berdampak pada rendahnya kemampuan berhitung pada anak.

Secara umum, kelas eksperimen mempunyai sikap yang positif terhadap pembelajaran yang dilakukan. Hal ini dapat dilihat dari proses pembelajaran, dimana anak lebih nyaman dalam belajar, lebih menyenangkan dan minat anak terhadap konsep berhitung dapat meningkat karena menggunakan pembelajaran yang tidak biasa digunakan oleh guru di sekolah yaitu dengan menggunakan metode jarimatika. Anak tidak hanya mengenal bilangan tetapi juga anak belajar sambil bermain dan mengasah fsikomotriknya dengan menggunakan jari-jari tangannya. Hal ini sejalan dengan penelitian yang dilakukan oleh (Mudiyatun, 2015) yang menyatakan bahwa melalui metode jarimatika mampu meningkatkan kemampuan berhitung permulaan anak.

\section{KESIMPULAN}

Berdasarkan hasil analisis data dan pembahasan diperoleh kesimmpulan sebagai berikut:

1. Kemampuan berhitung anak usia dini pada kelas eksperimen mengalami peningkatan. Hal ini terlihat dari hasil rata-rata $\mathrm{N}$-gain kelas eksperimen yaitu sebesar 0,65 yang berada pada kategori sedang sehingga kemampuan berhitung anak yang pembelajarannya menggunakan metode jarimatika lebih baik daripada yang menggunakan metode biasa.

2. Pembelajaran dengan menggunakan metode jarimatika dapat membuat pembelajaran lebih menyenangkan karena selain belajar anak juga diajak untuk bermain dengan mengasah kemampuan kogntif dan fsikomotoriknya melalui permainan dengan menggunakan jari.

\section{DAFTAR PUSTAKA}

Elsap, D. S. (2018). Analisis Faktor Yang Mempengaruhi Peningkatan Karakter dan Motivasi Belajar Anak Melalui Pendidikan Non Formal (Studi Kasus di Bimbingan Belajar Aljabar). Jurnal Pendidikan Nonformal, 13(2), 8591.

Hardiyanti, S., Maulana, M., \& Julia, J. (2017). Pengaruh Pendekatan Kontekstual Berbantuan Jarimatika terhadap Kemampuan Pemahaman Matematis dan Keterampilan Berhitung Siswa pada Materi Perkalian. Jurnal UPI, 881-890.

Minarti, E. D., \& Nurfauziah, P. (2016). Pendekatan Kontruktivisme dengan Model Pembelajaran Generatif Guna Meningkatkan Kemampuan Komunikasi dan Koneksi Matematis serta Self Efficacy mahasiswa Calon Guru Di Kota Cimahi. Jurnal P2M STKIP 


\section{JURNAL GERIA}

ISSN : 2614-6347(Print) 2714-4107 (Online)

Vol.2 | No.6 | November 2019

Silwangi, 3(2), 68-83.

Mudiyatun, S. P. (2015). Meningkatkan kemampuan Berhitung Permulaan Menggunakan Metode Jarimatika pada Anak Kelompok A TK Harapan II Magelang. Jurnal Pendidikan Guru Pendidikan Anak Usia Dini, 4(November), 1-9.

Musi, M. A. (2016). Peningkatakan Keterampilan Berhitung Anak Usia Taman Kanak-Kanak Melalui Demonstrasi dengan Media Gambar. Jurnal Penelitian Pendidikan INSANI, 19(1), 36-41.

Oktariyani, N. (2017). Peningkatan Kemampuan Berhitung Anak Usia Dini Melalui Permainan Lingkaran Angka di Taman Kanak-Kanak Qatrinnada Kecamatan Koto Tangah Padang. Jurnal Pendidikan
Anak Usia Dini, 1(1), 83-96.

Patintingan, M. L. (2015). Penerapan Metode Jarimatika Di TK Asoka Makassar. JUrnal KIP, 4(1), 733747.

Purwaningsih, S. J., Reswita, \& Putri, A. A. (2018). Meningkatkan Kemampuan Berhitung dengan Menggunakan Metode Jarimatika pada Anak Usia 4-5 Tahun di PAUD Dinda Kids Kota Pekan Baru. Jurnal Pendidikan Anak Usia Dini, 2(1), 49-60. 